\title{
UTJECAJ PUŠAC̆KIH NAVIKA, STAVOVA I EDUKACIJE LIJEČNIKA OBITELJSKE MEDICINE NA RAD SA PACIJENTIMA NA PRESTANKU PUŠENJA
}

\author{
Marin Kvaternik, Slađana Petković Šiljak \\ Institut za javno zdravstvo Republike Srpske, Banja Luka, Bosna i Hercegovina \\ Rad je primljen 4.3.2016. \\ Rad je korigiran 24.3.2016. \\ Rad je prihvaćen 15.4.2016.
}

\section{SAŽETAK}

UVOD: Savjeti liječnika obiteljske medicine značajno utječu na prestanak pušenja. Unatoč tome, željeni i očekivani stupanj uključenosti liječnika obiteljske medicine često nije dostignut. Međunarodna istraživanja su kao neke od ključnih uzroka ovakvog stanja naveli edukaciju, negativne stavove prema ovoj vrsti intervencije i pušački status liječnika.

CILJ: Utvrditi utjecaj edukacije i stavova liječnika obiteljske medicine u Republici Srpskoj, kao i njihovih pušačkih navika na podršku u odvikavanju od pušenja.

ISPITANICI I METODE: Istraživanje je provedeno kao studija presjeka, na reprezentativnom uzorku liječnika obiteljske medicine u Republici Srpskoj. Instrument istraživanja je anketni upitnik koji su ispitanici sami popunjavali. Razina angažmana liječnika obiteljske medicine u odvikavanju od pušenja je analizirana na temelju njihovih odgovora o okolnostima za razgovor s pacijentima o pušenju, pri čemu je rutinski rad podrazumjevao najviši stupanj, ukoliko to rade tek prilikom pojave simptoma bolesti-niži, a ako to rijetko rade-najnižu razinu angažiranja. Pored osnovnih statističkih metoda, dobiveni podaci su statistički analizirani uz korištenje hi kvadrat testa.

REZULTATI: Dodatno educirani liječnici u većem postotku obavljaju aktivnost rutinski i to na razini statističke značajnosti $(\mathrm{p}=0,011)$. Ispitanici koji smatraju da je moguće vrlo mnogo pomoći u većem postotku i obavljaju aktivnost rutinski. Liječnici nepušači u većem postotku obavljaju ovu aktivnost rutinski uz statistički značajnu razliku $(\mathrm{p}=0,040)$.

ZAKLJUČAK:Pušački status doktora obiteljske medicine i njihova edukacija utječu na rad na prestanku pušenja i to na razini statističke značajnosti, dok uvjerenja istih u vezi pomoći pušačima u odvikavanju utječu na rad ali bez statistički značajne razlike.

Ključne riječi: pušenje, odvikavanje, obiteljska medicina

Osoba za razmjenu informacija:

Marin Kvaternik

E-mail: marin.k@teol.net

\section{UVOD}

Pušenje kao čimbenik rizika u nastanku vodećih masovnih kroničnih nezaraznih bolesti, vodeći je pojedinačni preventabilni uzrok prijevremene smrti. Pedesetogodišnja prospektivna studija, provedena među britanskim liječnicima, pokazala je trostruko veću dobno specifičnu stopu smrtnosti među pušačima, prosječno 10 godina kraći životni vijek pušača, te koristi od prestanka pušenja (1). Stoga se među šest isplativih intervencija koje predlaže Okvirna konvencija za kontrolu duhana nalazi i pomoć ljudima da prestanu pušiti (2).O značaju uključivanja liječnika u aktivnosti prestanka pušenja pokazali su rezultati meta analize određenih istraživanja prema kojima su savjeti liječnika za prestanak pušenja proizveli kod pušača stopu prestanka od $10,2 \%$ za razliku od stope prestanka od 7,9 \% kod pušača bez ove vrste potpore (3). Populacijske studije, međutim, dosljedno pokazuju da u praksi velika većina pušača koji trajno prestanu pušiti učini to bez bilo kakvog oblika pomoći (4-6).

$\mathrm{U}$ provedbi preventivnih programa, uključujući upravo i programe prestanka pušenja, u 
zdravstvenim sustavima svih zemalja, prepoznata je ključna uloga liječnika opće/obiteljske medicine (7). Unatoč tome, željeni i očekivani stupanj uključenosti liječnika obiteljske medicine u preventivne aktivnosti često nije dostignut (8). U cilju utvrđivanja razloga za ovakvu praksu, vršena su među liječnicima obiteljske medicine brojna istraživanja. Za unapređenje i veću uključenost liječnika obiteljske medicine u promociju prestanka pušenja ključni faktor je, prema takvim istraživanjima, njihova odgovarajuća edukacija, stjecanje novih znanja i vještina, uz savladavanje negativnih stavova i niske samoučinkovitosti, kao i vlastite pušačke navike $(9,10)$.

U Republici Srpskoj se od 2003. godine provodi Program prevencije i kontrole nezaraznih bolesti (Program). Jedna od ključnih kompnenti ovog Programa je odvikavanje od pušenja uz podršku obiteljske medicine. Obzirom na iznesena međunarodna iskustva, au cilju unapređenja rada na prestanku pušenja,smatrali smo da bi bilo značajno istražiti utjecaj pušačkih navika, edukacije i stavova liječnika obiteljske medicine u Republici Srpskoj na njihovu potporu pušačima u odvikavanju od pušenja.

\section{ISPITANICI I METODE}

Istraživanje je provedeno kao studija presjeka, na reprezentativnom uzorku liječnika obiteljske medicine 40 Domova zdravlja u Republici Srpskoj. Instrument istraživanja je bio anketni upitnikkoji su ispitanici sami popunjavali. Anketiranje su vršili djelatnici Instituta za javno zdravstvo Republike Srpske odlaskom u Domove zdravlja. Anketni upitnik je sadržavao pitanja o pušačkom statusu ispitanika (pušač, biviši pušač, nepušač), o završenoj edukaciji iz odvikavanja od pušenja, te stav o mogućnosti liječnika da pomogne prilikom odvikavanja (veoma malo do veoma mnogo). Razina angažmana liječnika obiteljske medicine u odvikavanju od pušenja je dobivena na temelju njihovih odgovora o okolnostima za razgovor s pacijentima o pušenju, pri čemu je rutinski rad podrazumjevao najviši stupanj, ukoliko to rade tek prilikom pojave simptoma bolesti- niži, a ako to rijetko rade- najnižu razinu angažiranja. Križanjem odgovora na pitanja o edukaciji, pušačkom statusu liječnika i njihovim stavovima $s$ razinom angažmana na odvikavanju od pušenja nastojalo se dobiti odgovore na postavljene ciljeve rada. Obrađeni podaci su prezentirani u vidu tablica, uz tekstualni komentar. Statistička značajnost dobivenih rezultata testirana je korištenjem hi kvadrat testa. Obrada podataka je vršena uz korištenje standardnog SPSS 17.0 programa.

\section{REZULTATI}

U istraživanje su bila uključena 273 liječnika obiteljske medicine. U tablici 1. prikazan je odnos edukacije iz odvikavanja od pušenja i okolnosti za razgovor s pacijentima o pušenju. Okolnost u kojoj se najčešće razgovara s pacijentom o temi pušačka navika je prilikom rutinske posjete pacijenta $(72,5 \%)$. Dodatno educirani liječnici statistički značajno učestalije obavljaju aktivnost rutinski $(\mathrm{p}=0,011)$.

Tablica 1. Edukacija iz odvikavanju od pušenja $i$ okolnosti za razgovor s pacijentima o pušenju

\begin{tabular}{cccccc}
\hline & $\begin{array}{c}\text { Edukacija iz } \\
\text { odvikavanja od pušenja }\end{array}$ & $\begin{array}{c}\text { Broj } \\
\text { odgovora }\end{array}$ & Simptomi & Rutinski & Rijetko \\
\hline Liječnici & $\mathrm{Da}$ & 187 & $23,0 \%$ & $77,0 \%$ & $0,0 \%$ \\
& $\mathrm{Ne}$ & 86 & $34,9 \%$ & $62,8 \%$ & $2,3 \%$ \\
\hline
\end{tabular}

Odnos uvjerenja liječnika u vezi mogućnosti da pomognu pušačima i okolnosti za razgovor s pacijentima o pušenju prikazan je u tablici 2. Ispitanici koji smatraju da je moguće vrlo mnogo pomoći u većem postotku i obavljaju aktivnost rutinski.

Tablica 2. Pomoć liječnika obiteljske medicine kod prestanka pušenja i okolnosti za razgovor sa pacijentima o pušenju

\begin{tabular}{cccccc}
\hline & $\begin{array}{c}\text { Pomoć liječnika kod } \\
\text { odvikavanja od pušenja }\end{array}$ & $\begin{array}{c}\text { Broj } \\
\text { odgovora }\end{array}$ & Simptomi & Rutinski & Rijetko \\
\hline \multirow{2}{*}{ Liječnici } & Veoma malo & 35 & $34,3 \%$ & $62,9 \%$ & $2,9 \%$ \\
& Malo & 77 & $28,6 \%$ & $70,1 \%$ & $1,3 \%$ \\
& Ni malo ni mnogo & 65 & $26,2 \%$ & $73,8 \%$ & $0,0 \%$ \\
& Mnogo & 69 & $23,2 \%$ & $76,8 \%$ & $0,0 \%$ \\
& Veoma mnogo & 26 & $23,1 \%$ & $76,9 \%$ & $0,0 \%$ \\
\hline
\end{tabular}

Unakrsna analiza pušačkog statusa liječnika obiteljske medicine i razine aktivnosti na prestanku pušenja prikazana je u tablici 3. Liječnici nepušači statistički značajno učestalije obavljaju ovu aktivnost rutinski u odnosu na liječnike pušače $(\mathrm{p}=0,040)$. 
Tabela 3. Pušačka navika liječnika obiteljske medicine i okolnosti za razgovor sa pacijentima o odvikavanju od pušenje

\begin{tabular}{cccccc}
\hline & $\begin{array}{c}\text { Pušăcka navika } \\
\text { doktora }\end{array}$ & Broj odgovora & Simptomi & Rutinski & Rijetko \\
\hline Liječnici & Pušač & 59 & $35,6 \%$ & $64,4 \%$ & $0,0 \%$ \\
& Nepušač & 174 & $20,7 \%$ & $78,2 \%$ & $1,1 \%$ \\
& Biš̌i pušač & 40 & $40,0 \%$ & $60,0 \%$ & $0,0 \%$ \\
\hline
\end{tabular}

\section{RASPRAVA}

Da bi bilo koji program prevencije bio uspješan, neophodan je proaktivan pristup zdravstvenih djelatnika. Međutim, većina procjena rizika u općoj/obiteljskoj medicini se provodi oportunistički (11). Dodatni problem je što povod za razgovor o bolesnikovim životnim navikama liječnici obiteljske medicine najčešće nalaze u pojavi simptoma bolesti. To je pokazala i studija provedena u četiri nordijske države (Švedska, Norveška, Finska, Island), gdje se liječnici obiteljske medicine najčešće o pacijentovim navikama raspituju kad se pojave simptomi povezani s pušenjem iako većina doktora percipira razgovor o pušenju sa svojim pacijentima kao dio svakodnevnog rada (12). Mada i kod doktora obiteljske medicine u Republici Srpskoj izostaje proaktivan pristup u prevenciji kroničnih nezaraznih bolesti(13), u našem istraživanju bilježimo da oko četvrtine liječnika obiteljske medicine (26,7 \%) započinje razgovor o pušačkim navikama sa svojim pacijentima tek kod pojave simptoma bolesti povezane s pušenjem, a da praktično većina ostalih $(72,5 \%)$, to čini rutinski. Brojna međunarodna istraživanja među liječnicima obiteljske medicine iznose priznanja istih u vezi nedostatka vještina potrebnih za djelotvoran rad na prevenciji stilova života uopće,posebno pušenja $(14,15)$. A da stjecanje posebnih znanja i vještina u odvikavanju od pušenja daje praktične rezultate, pokazala su brojna međunarodna istraživanja, od povećanja razine aktivnosti, do toga da obuka liječnika za intervencije prestanka pušenja dovodi do boljih rezultata (16-18). Naše istraživanje jepokazalo da edukacija dovodi do češćeg angažiranja liječnika koji su prošli odgovarajuću edukaciju za rad na prestanku pušenja u odnosu na needuciraneliječnike, i to na razini statistički značajne razlike. Ovi rezultati su na određen način potvrdili nalaze jednog ranijeg istraživanja provedenog u Republici Srpskoj, neposredno nakon obavljene edukacije liječnika obiteljske medicine (19) Na ovaj način dolazimo do zaključka da određeni pozitivni efekti edukacije na praksu postoje i nekoliko godina nakon iste. Istodobno treba naglasiti potrebu kontinuirane edukacije pri čemu treba vršiti stalnu procjenu obrazovnih programa i prakse kako bi se uočene praznine popunile.

Drugi zadatak rada je bio utvrditi utjecaj uvjerenja liječnika obiteljske medicine u njihov rad na odvikavanju od pušenja. Mada nije postojala statistički značajna razlika u distribuciji odgovora među liječnicima o okolnostima za razgovor o pušačkoj navici u odnosu na mišljenje ispitanika o tome koliko liječnik obiteljske medicine može pomoći kod odvikavanja od pušenja, s rastom njihovog pozitivnog uvjerenja u vezi pomoći liječnika kod odvikavanja od pušenja konstantno je rastao i postotak liječnika koji to rade rutinski. Interesantno je da 112 liječnika ili 41,2 \% smatra da liječnici mogu "malo" ili "vrlo malo" da pomognu kod odvikavanja od pušenja, što je slično nekim međunarodnim istraživanjima gdje $38 \%$ liječnika smatra neefikasnim rad s pacijentima na odvikavanju od pušenja (20).

Utjecaj pušačkih navika liječnika na njihov rad na odvikavanju od pušenja bio je tema mnogih međunarodnih istraživanja. Većina takvih istraživanja, zasnovana na samoizvještavanju samih liječnika, pokazala je postojanje utjecaja pušačkih navika liječnika na intervencije prestanka pušenja. Neka od tih istraživanja, kao studije u Austriji, Finskoj, Francuskoj i Grčkoj, našla su da liječnici nepušači značajno češće nego pušači pokreću pitanja pušenja (21-24). Neka druga istraživanja, poput komparativne studije 11 zemalja Europske unije, došle su do istih rezultata s tim da ta razlika nije bila i statistički značajna (25). Mada manje brojna, postoje i istraživanja koja nisu utvrdila utjecaj "pušačkog statusa" doktora na razinu savjetovanja pacijenata u vezi pušenja (26).

U Republici Srpskoj svaki peti liječnik obiteljske medicine je pušač (27). Prema rezultatima našeg rada liječnici obiteljske medicine nepušači pokreću pitanje pušenja češće od svojih kolega pušača i to 
na razini statističke značajnosti. Interesantno je da liječnici bivši pušači rjeđe rutinski pokreću pitanje pušenja od kolega pušača. Prethodno spomenuta ispitivanja, pa tako niti naše, nisu se posebno bavila odnosom liječnika bivših pušača prema intervencijama prestanka pušenja. Jedna skorašnja studija provedena u Poljskoj pokazala je vrlo zanimljiva, rekli bi pozitivna iskustva pušača, kada je liječnik-bivši pušač, predstavio problem odvikavanja od pušenja duhana ne iz medicinskog kuta, već iz perspektive pušača (28). Ova saznanja bi mogla biti poticaj za istraživanja koja bi se bavila odnosom liječnika bivših pušača i uspješnosti odvikavanja od pušenja.

\section{ZAKLJUČCI}

Razgovor s pacijentima o pušačkim navikama je kod većine liječnika obiteljske medicine Republike Srpske dio njihovog rutinskog rada. Istovremeno, liječnici nepušači i liječnici sa završenom dodatnom edukacijom za rad na odvikavanju od pušenja češće rutinski pokreću razgovor o pušenju sa svojim pacijentima u odnosu na svoje kolege pušače i one koji nemaju dodatnu edukaciju, i to na razini statističke značajnosti.Uvjerenja liječnika u efekte liječničke podrške pušačima u odvikavanju od pušenja utječu na praksu ali bez statističke značajnosti.

\section{LITERATURA}

1. Doll R, Peto R, Boreham J, Sutherland I. Mortality in relation to smoking: 50 years' observations on male British doctors. BMJ. 2004;328:1519-28.

2. WHO. Framework Convention on Tobacco Control 2003. updated reprint 2004.

3. Fiore MC, Jaén CR, Baker TB, Bailey WC, Bennett G, Benowitz NL, i sur. Clinical practice guideline: treating tobacco use and dependence: 2008 update. Rockville, MD: U.S. Department of Health and Human Services,Public Health Service.

4. Zhu S, Melcer T, Sun J, Rosbrook B, Pierce JP. Smoking cessation with and without assistance: a population-based analysis. Am J Prev Med. 2000;18:305-11.

5. Walsh RA, Paul CL, Tzelepis F, Stojanovski E. Quit smoking behaviours and intentions and hard-core smoking in New South Wales. Health Promot J Austr. 2006;17:54-60.

6. Solberg LI, Asche SE, Boyle R, McCarty MC, Thoele MJ. Smoking and cessation behaviors among young adults of various educational backgrounds. Am J Public Health. 2007;97:1421-26.

7. Katić M, Juresa V, Bergman-Marković B, Jurković $\mathrm{D}$, Predavec $\mathrm{S}$, Hrastinski M, i sur. Preventive work family medicine proactive approach. Acta Med Croatica. 2010;64;443-52.

8. Liseckiene I, Boerma GW, Milasauskiene Z, Valius L, Miseviciene I, Groenewegen PP. Primary care in a postcomunist country 10 years later. Comparison of service profi les of Lithuanian primary care physicians in 1994 and GPs in 2004. Health Policy. 2007;83:105-13.

9. Twardella $\mathrm{D}$, Brenner $\mathrm{H}$. Lack of training as a central barrier to the promotion of smoking cessatin: a survey amnog general practitioners in Germany. Eur J Public Health. 2005;15:140-45.

10. Lancaster T, Silagy C, Fowler G. Training health professionals in smoking cessation. Cochrane Database Syst Rev. 2000;3:CD000214

11. Harris M, Lloyd J. The role of Australien primary health care in the prevention of chronic disease. Australien National Preventive Health Agency. 2012.

12. Helgason AR, Lund KE. General practitioners' perceived barriers to smoking cessation-related from four Nordic countries. Scand J Public Health. 2002;30:141-147

13. Kvaternik M. Faktori koji utiču na rad porodične medicine na prevenciji nezaraznih bolesti. Doktorska disertacija. Panevropski univerzitet Banja Luka: Banja Luka; 2014.

14. Laws R, Kirby S, Powell Davies G, Williams AM, Jayasinghe UW, Amoroso CL, Harris MF. "Should I and can I?": a mixed methods study of clinician beliefs and attitudes in the management of lifestyle risk factors in primary health care'. BMC Health Services Research 2008;8. Available at: www.ncbi.nlm.nih.gov/pmc/articles/ PMC2267185/ (accessed on 12 August 2010).

15. Braun BL, Fowles JB, Solberg LI, Kind EA, Lando $\mathrm{H}$, Pine D . 'Smoking related attitudes and cli- 
nical practices of medical personnel in Minnesota. American Journal of Preventive Medicine 2004;27:316-22

16. Prignot J, Bartsch P, Vermeire P, Jamart J, Wanlin M, Uydebrouck M, i sur. Physician's involvement in the smoking cessation process of their patients. Results of a 1998 survey among 4643 Belgian physicians. Acta Clin Belg 2000;55:266-75

17. Boldemann C, Gilljam H, Lund KE, Helgason AR. Smoking cessation in general practice: the effects of a quitline. Nicotine Tob Res. 2006;8:785-90.

18. Boyce T, Peckham S, Hann A, Trenholm S. A pro-active approach. Health Promotion and Ill-health prevention. The King s Fund. 2010.

19. Kvaternik M. Impact of Education on the Work of Doctor of Medicine with Smokers on Smoking Cessation. Materia Socio Medica. 2009;21:229-31.

20. Vogt F, Hall S, Marteau TM . General practitioners and family physicians'negative beliefs and attitudes towards discussing smoking cessation with patients:a systematic review' Addiction. 2005;1423-31.

21. Kössler W, Lanzenberger M, Zwick H. Smoking habits of office-based general practitioners and internists in Austria and their smoking cessation efforts. Wien Klin Wochenschr. 2002;11:762-65.

22. Barengo NC, Sandstrom HP, Jormanainen VJ, Myllykangas MT. Attitudes and behaviours in smoking cessation among general practitioners in Finland 2001. Soz Praventivmed. 2005;50:355-60.
23. Tessier JF, René L, Nejjari C, Belougne D, Moulin J, Freour P. Attitudes and opinions of French general practitioners towards tobacco. Tob Control. 1993;2:226-230.

24. Sotiropoulos A, Gikas A, Spanou E, Dimitrelos D, Karakostas F, Skliros E.. Smoking habits and associated factors among Greek physicians. Public Health. 2007;121:333-40.

25. Brotons C, Bjorkelund C, Bulc M. Prevention and health promotion in clinical practice: The views of general practitioners in Europe. Prev Med. 2005;41:595-601.

26. Ulbricht S, Meyer C, Schumann A, et al. Provision of smoking cessation counseling by general practitioners assisted by training and screening procedure. Patient Educ Couns. 2006;63:232-38.

27. Kvaternik M. Koliko zdravstveni radnici porodične medicine misle o svom zdravlju. Zbornik radova Sedmi mađunarodni kongres „Ekologija, zdravlje, rad, sport" Banja Luka, 21-23. maj 2015.

28. Buczkowski K, Marcinowicz L, Czachowski S, Piszczek E, Sowinska A. "What kind of general practitioner do I need for smoking cessation?" Results from a qualitative study in Poland. $B M C$ Family Practice 2013;14:159 


\title{
THE IMPACT OF SMOKING HABITS ATTITUDES AND EDUCATION OF FAMILY PHYSICIANS TO WORK WITH PATIENTS ON SMOKING CESSATION
}

\author{
Marin Kvaternik, Slađana Petković Šiljak \\ Institute of Public Health of the Republic of Srpska, Banja Luka, Bosnia and Herzegovina
}

\begin{abstract}
INTRODUCTION: Family physician's advice significantly affects smoking cessation. Nevertheless, the desired and expected level of involvement of family physicians is often not reached. International research listed several reasons for this kind of attitude: training, negative attitudes towards this type of intervention, and the physician's smoking status.

SUBJECTS AND METHODS: The study was conducted as a cross-sectional study, on a representative sample of family physicians in the Republic of Srpska. The survey instrument was a questionnaire which was filled out by the participants. The level of involvement of family physicians in smoking cessation was analyzed on the basis of their answers according to the circumstances to talk with patients about smoking, whereby routine work implied the highest level, and intervention only upon the occurrence of symptoms the lowest level, and if they rarely talk to patients about their smoking habits the lowest level of engagement. Besides the basic statistical methods, the data were statistically analyzed using the chi-square test.

RESULTS: Physicians who were additionally educated were more likely perform the routine activity at the level of statistical significance $(\mathrm{p}=0.011)$. Respondents who believe that it is possible to be more helpful in a higher percentage perform the activity routinely. Physicians who are non-smokers were more likely to perform this activity routinely with a statistically significant difference $(\mathrm{p}=0.040)$.

CONCLUSION: The smoking status of family medicine physicians and their education influence the work on smoking cessation at the level of statistical significance, while the same beliefs about helping smokers to quit influence the work but without statistically significant differences.
\end{abstract}

Key words: smoking, cessation, family medicine

Correspondence: Marin Kvaternik

E-mail: marin.k@teol.net 